http://dx.doi.org/10.35381/racji.v5i1.620

\title{
Defensa de los derechos del trabajador migrante a través de políticas públicas estatales
}

\section{Defense of the migrant worker's rights through state public policies}

\author{
Israel Oswaldo Solís-Arichavala \\ israel.solis@psg.ucacue.edu.ec \\ Universidad Católica de Cuenca, Cuenca \\ Ecuador \\ https://orcid.org/0000-0003-0440-3192 \\ Cecilia Ivonne Narváez-Zurita \\ inarvaez@ucacue.edu.ec \\ Universidad Católica de Cuenca, Cuenca \\ Ecuador \\ https://orcid.org/0000-0002-7437-9880 \\ Enrique Eugenio Pozo-Cabrera \\ epozo@ucacue.edu.ec \\ Universidad Católica de Cuenca, Cuenca \\ Ecuador \\ https://orcid.org/0000-0003-4980-6403 \\ Juan Carlos Erazo-Álvarez \\ jcerazo@ucacue.edu.ec \\ Universidad Católica de Cuenca, Cuenca \\ Ecuador \\ https://orcid.org/0000-0001-6480-2270
}

Recibido: 14 de noviembre de 2019

Aprobado: 15 de diciembre de 2019

\section{RESUMEN}

El marco regulador de migración no ha registrado cambios sustanciales hasta el momento en lo que respecta a migración laboral, sobre la base de esta problemática, el presente artículo tiene por objetivo analizar las políticas estatales desarrolladas en Ecuador encaminadas a proteger los derechos de los trabajadores migrantes, como 
mecanismo de determinación de una línea base de fundamentos jurídicos sobre la red compleja de normas y procedimientos expuestos en la Constitución. La metodología utilizada se enmarco en el paradigma cualitativo mediante un enfoque multimetódico en el que se logró un acercamiento interpretativo de las políticas públicas migratorias, lo cual implico estudiar las variables en su ambiente natural. Como resultado del estudio se concluye que los migrantes no están siendo considerados tal como lo establece la Constitución de la República del Ecuador. El Estado busca la creación de políticas públicas que se adecuen a la realidad migratoria del país.

Descriptores: Trabajo; migración; política pública; constitución; Estado.

\section{ABSTRACT}

The regulatory framework of migration has not registered substantial changes so far in regard to labor migration, based on this problem, this article aims to analyze the state policies developed in Ecuador aimed at protecting the rights of migrant workers, as a mechanism for determining a baseline of legal bases on the complex network of rules and procedures set forth in the Constitution. The methodology used was framed in the qualitative paradigm through a multimethodic approach in which an interpretative approach to migratory public policies was achieved, which involved studying the variables in their natural environment. As a result of the study it is concluded that migrants are not being considered as established by the Constitution of the Republic of Ecuador. The State seeks the creation of public policies that adapt to the migratory reality of the country.

Descriptors: Job; migration, publics politics; constitution; State.

\section{INTRODUCCIÓN}

El Derecho Constitucional en el Ecuador se conforma dentro de una serie de paradigmas donde se valida lo político, lo legal y lo legitimo. Por eso sin dejar de lado la constitución como norma suprema del Estado se debe erigir una concepción jurídica para establecer un camino en el que el constitucionalismo implique gestar una institucionalidad que asegure la eficacia de los derechos expuestos en la constitución (Grijalva, 2011). En este contexto, la Constitución de la República y la Ley Orgánica de Movilidad Humana desempeñan un rol preponderante en la promoción, protección y 
aplicación de los derechos de los migrantes, los mismos que guardan correlación con los estándares internacionales.

Dentro de este marco, la migración se ha convertido en los últimos tiempos en un fenómeno que presenta un significativo interés (Aldana Zavala \& Isea, 2019), debido a todos los factores que tiene inmersos, ya que va desde un análisis coyuntural y paradigmático hasta un análisis histórico, en el que se estudian las causas y consecuencias de dicho fenómeno. Las variables en las que se sustenta la migración van desde lo social, lo político, lo económico entre otras. Todas se articulan con la finalidad de entender cuáles son estos procesos y como la comunidad internacional está estableciendo pautas para formular planes de acción.

Es así que, se intenta comprender y considerar la defensa de los derechos del trabajador migrante a través de políticas públicas estatales, ya que la migración se ha convertido en los últimos tiempos en un fenómeno que presenta un significativo interés. Por ello, este artículo analiza los elementos consagrados en la Constitución de la República del Ecuador y en la Ley Orgánica de Movilidad Humana, sobre los derechos de los trabajadores migrantes y su defensa a través de las políticas públicas, como garantía de un trabajo estable, una justa remuneración y acceso a la salud pública. Entre otros elementos que se consideran en el estudio, están los procesos y la fundamentación jurídica y normativa migratoria que se está dando en diferentes países estos desde el Derecho Comparado. Así como también los campos de acción y los elementos que se han fundamentado en posicionamientos jurídicos y constitucionales, con leyes que intentan establecer el sustento jurídico y convertirse en el cimiento de una política.

Por lo antes expuesto, el presente artículo tiene por objetivo analizar las políticas estatales desarrolladas en Ecuador encaminadas a proteger los derechos de los trabajadores migrantes, como mecanismo de determinación de una línea base de fundamentos jurídicos sobre esta red compleja de normas y procedimientos expuestos en la Constitución. Es así que, el Ecuador se convierte en un referente en este sentido, 
ya que busca generar políticas ligadas a planes de acción integral en el cual prime los derechos de los ciudadanos, y que por otro lado se respete los derechos de los migrantes. Esto con el fin de concatenar nuevos espacios, en los que se sustente el dialogo y una amalgama de experiencias, que busquen un bien común.

\section{DESARROLLO}

\section{Procesos de migración, historia y políticas públicas en el Ecuador y la región}

Los movimientos migratorios hoy en día se han convertido en un tema de análisis. Los cambios sociales y estructurales de la sociedad se basan mucho en la generación de un entendimiento propio del sistema social. Por otro lado, se encuentra la necesidad de establecer políticas públicas como parte fundamental en el accionar de los gobiernos y la sociedad, es así, que el estudio de las políticas públicas constituye un proceso altamente complejo, debido a los diferentes factores que intervienen en la misma (Sabatier, 2010). En consecuencia, el diseño de políticas públicas migratorias que es lo que analiza este artículo, se enraíza en una serie de lineamientos de carácter jurídico, económico, político y social, todo esto a fin de entender las dinámicas que confluyen en torno a esta problemática.

Las intensas corrientes migratorias constituyen un proceso que ha cambiado la fisonomía de los paisajes. Estas dinámicas se han convertido en catalizadores de procesos que involucran cambios sustantivos, se han conformado sociedades multiculturales impulsadas por la llegada de los inmigrantes (Velasco, 2005), en cuanto a la globalización, ésta ha formulado una transformación radical, en la que se ve inmersa la complejidad de los intercambios sociales transnacionales poniendo en tela de juicio procesos como la migración que han irrumpido en la cotidianeidad de las personas y grupos sociales. También se debe analizar el hecho que la migración ha alcanzado su punto más alto; en la última década son varias las personas (refugiados, víctima de trata apátridas, migrantes indocumentados y exiliados) que han nutrido ese 
conflicto migratorio político, social y económico que algunos países experimentan (Iranzo, 2016).

Es por eso que, se ha tratado de buscar soluciones que nacen desde la iniciativa de los gobiernos y organizaciones internacionales como el Banco Mundial (BM) y La Organización de Naciones Unidas (ONU), quienes han establecido los siguientes parámetros claves que se enmarcan en la creación de un plan de acción ante el fenómeno migratorio: 1. Reformular la migración en clave positiva de desarrollo de los países expulsores, 2. Promover la existencia de buenos gobiernos en el Estado de origen, 3. Ordenar las migraciones transnacionales a través de políticas públicas eficientes, y 4. Incluir en los regímenes de extranjería de los Estados receptores el enfoque de derechos humanos (Iranzo, 2016).

Un referente mundial en la creación de leyes para los inmigrantes son los Estados Unidos de Norte América, este país a través de la formulación de leyes estatales antinmigrantes ha conformado una especie de sincretismo migratorio atado a regulaciones que atentan en mucho de los casos contra los derechos humanos, como es el caso de la ley SB1070, del Estado de Arizona (Velasco , 2005), en la cual se exponen artículos de ley que coartan la esencia de procesos migratorios acordes al entendimiento de los derechos humanos como parte fundamental de la convivencia plena de las naciones.

En el caso de España, por ejemplo, su sistema migratorio se caracteriza por irregularidades como consecuencia de una mala gestión por parte de la policía, lo que genera procesos de injusticia social que se caracterizan por el cometimiento de delitos en contra de los derechos humanos (Ansolabehere y Vásquez, 2017). En tanto los inmigrantes buscan desde sus Estados receptores que estos ofrezcan garantías como el acceso a la ciudadanía, lo que se ha convertido en un verdadero talón De Aquiles en la implementación de políticas públicas acordes a las necesidades presentadas por estos flujos migratorios. 
Respecto a la migración por trabajo al ser humano se lo cataloga o se lo ve como una mercancía, y en este punto la libre circulación ya no radica en la libre movilidad de las personas, sino como parte de un paquete compuesto por la libre circulación de capitales (Ermida , 2009). Atendiendo estas consideraciones, es posible estudiar la migración, el trabajo y las leyes que se establecen en el contexto ecuatoriano, ya que existen dicotomías, divergencias y conflictos que se están dando actualmente en el país a consecuencia de este fenómeno global, el cual está llevando a la nación a un caos interno por la falta de políticas públicas que permitan identificar, diagnosticar, planificar y ejecutar proyectos acordes a la realidad y sobre todo a la necesidad que tiene este territorio.

En los últimos años el desplazamiento de extranjeros al Ecuador ha mantenido una tendencia ascendente sostenida, quienes han llegado al país en búsqueda de mejores oportunidades de empleo y mejores condiciones de vida. Esta situación sin duda ha trastocado duramente la conducta de la sociedad ecuatoriana, generando en algunos casos cambios positivos y en otros negativos, es así que, ante esta realidad, se emitió el decreto presidencial 826 en el 2018 que fija visa para los ciudadanos de Venezuela y amnistía para inmigrantes que no han violado la ley en Ecuador, convirtiéndose ésta en una medida emergente por cuanto no existe un componente previo que se esgrima en responder las falencias de planificación en torno a políticas migratorias que tiene el país, dejando aún más en evidencia las deficiencias a nivel de gobierno central en cuanto a la determinación y difusión de derechos que amparen a la comunidad migrante.

A pesar de lo indicado, es necesario analizar los procesos garantistas que se establecen en la constitución del país, ya que el artículo 9 de la carta magna determina que las personas extranjeras que se encuentran en el territorio ecuatoriano tendrán los mismo derechos y deberes que los ecuatorianos ( Asamblea Nacional Constituyente, 2008). Sin embargo, dichas personas no tienen acceso a trabajos justos ni remunerados, ni seguridad social. Por lo tanto, se han formulado normativas nacionales 
como la Ley Orgánica de Movilidad Humana, la cual reconoce el derecho a la libre movilidad responsable y migración segura, en condiciones de respeto (Asamblea Nacional, 2017).

Bajo este contexto, son varios los factores que se deben estudiar para realizar una política pública acorde a las necesidades que se presentan en el país. La pregunta central que abarcan esta temática es: ¿Cuánto afecta la migración hacia el Ecuador? ; para responder esta interrogante es necesario recordar que en el conteniente americano se han vivido varias emergencias humanitarias, destacándose los casos de El Salvado, Colombia, Cuba y Haití, a consecuencia de la crisis económica - social de estas naciones, desatando olas de escases de alimentos, medicamentos, servicios básicos, entre otros, que provocaron que miles de sus habitantes migren de forma irregular hacia otros países, como una medida estratégica de supervivencia.

Ahora bien, para efectos de este trabajo, Ecuador es un país que a lo largo de su historia ha pasado distintos procesos migratorios, tanto a nivel interno como externo, los mismos que han incidido de forma continua en la configuración social, política, económica y cultural, por cuanto se ha considerado como un territorio receptor de migrantes, particularmente de colombianos, cubanos, chinos y venezolanos. Ante este fenómeno el gobierno ecuatoriano se vio en la necesidad de construir políticas migratorias como medidas para el desarrollo del país y bienestar de la población migrante.

Sin embargo, hasta la actualidad no se han generado verdaderas soluciones al tema migratorio, puesto que existen dos focos de atención que son recurrentes en el Ecuador, uno es la frontera de Rumichaca que colinda con Colombia, y el otro es la frontera con Perú, lugares donde se concentran los migrantes tanto para ingresar como para salir del país, estas zonas fronterizas carecen de la presentación de servicios de salud y otros elementos que permitan proteger a los migrantes que se encuentran en situación de vulnerabilidad (Bermudez, Mazuera, Albornoz y Morfle, 2018). Es así que los ultimos años, el país experimento un punto de quiebre en relaciones migratorias con 
la intensificación del movimiento migratorio venezolano, quienes promueven un proceso que busca entendimientos que nazcan desde la implementación de políticas públicas idóneas, las cuales se basen en el desarrollo integral de estos migrantes (Ramírez y Ramírez, 2005).

Bajo este escenario, se requiere el diseño de políticas públicas que articulen las diversas carteras de Estado y a la sociedad para responder de forma adecuada a los desafíos migratorios, en el marco del respeto de los derechos humanos, la no discriminación y no criminalización del proceso migratorio. En este orden de ideas, es importante realizar una comparación con los procesos en política migratoria que se están dando en países como Perú y Colombia, por ser países vecinos su realidad social presenta ciertas similitudes. Perú es un Estado descentralizado, con fuerte presencia migratoria, ante esta situación, en el 2011 se creó la Comisión Multisectorial Permanente denominada mesa de trabajo Intersectorial para la Gestión Migratoria (MTIGM), esta mesa se articula en ejes según la Agencia de la Organización de Naciones Unidas (ONU) para los Refugiados (2016).

En Perú en el año 2017 se crea el Decreto 1350 como nueva Ley de Migración, esta involucra y establece las bases de un derecho migratorio nacional, sustentado en derechos fundamentales. Esta ley se establece teniendo en cuenta los enfoques de: derechos humanos, género, inclusión social, protección asistencia y orientación al migrante y sobre todo apoyo a la inserción laboral. Con la firma de este decreto se facilita la migración de manera regular y ordenada. El artículo 1 del Decreto Legislativo 1350 (2017) regula el ingreso y salida del territorio peruano de personas nacionales y extranjeras, además regulariza la residencia y permanencia de personas extranjeras en el país. Por otro lado, sustenta la emisión de documentos de viaje tanto de nacionales como extranjeros, y de estos últimos los documentos de identidad.

La finalidad de este cuerpo normativo es contribuir la integración de los migrantes, garantizar los derechos a todas las personas nacionales y extranjeras, este proceso estará ligado al principio IV de la Constitución de la República del Perú, que sostiene 
que el Estado promoverá la integración del extranjero y su familia a la sociedad y cultura peruana (Congreso Constituyente Perú, 2019). Este país ha experimentado cambios en materia migratoria, producto de las exigencias en la formulación de política pública, que permita adecuar lineamientos y paradigmas migratorios a las necesidades del país, sobre todo en el manejo de los derechos humanos y regularización del trabajo.

En el caso colombiano, se realizaron cambios en materia jurídica migratoria, tales como resoluciones, decretos y leyes que regulan la política migratoria. Al gozar de amplitud el campo de análisis, impide entender como se ha venido desarrollando la migración en Colombia, por ello, esta investigación se rige particularmente al estudio del último decreto formulado en el año 2015, cuando se crea el Sistema Naciones, ente que regula los procesos de migración en el país (Gómez, 2009). En el año 2012, de igual manera se creó la Ley 795 de extranjería, con el Decreto 0834 (2013) "Los migrantes tendrán los mismos derechos y obligaciones que los nacionales, con algunas excepciones" (p.35), esta ley marca el hito que regula el paso de extranjeros por Colombia, reglamenta sus actividades y sobre todo formula políticas encaminadas al bienestar de este grupo social.

Sin embargo, hay que recalcar que este decreto no sintetiza la regularización del trabajo, para los migrantes que ingresen a al territorio ecuatoriano, así como no analiza la seguridad social, y otros elementos que permitan ejecutar una política pública acorde a las necesidades de los migrantes. Estas circunstancias generan desasosiego y abandono en las personas que migran hacia este país, es por eso que en los últimos años se ha convertido en un lugar de paso, para las personas que salen de sus países en busca de mejores días en los cuales se les garantice los derechos humanos (Heras, 2016).

Esta es la realidad latente en los países de Latinoamérica en materia migratoria. Tanto Colombia, Chile y Ecuador, disponen de constituciones de corte garantista, que ante crisis migratorias extremas se ven reducidas en su accionar y necesitan la ayuda de 
políticas públicas y de proyectos encaminados al bien común de su población. A partir del año 2012, debido a los procesos migratorios que se dan en la región, se establecen nuevos paradigmas, que en primera instancia desbordan las cualidades técnicas y logísticas de los países que reciben a los migrantes, es así que se comienzan a implementar herramientas fundamentadas desde lo jurídico, con el fin de establecer los lineamientos de políticas públicas en los países, es así que Colombia plantea su Ley de Migración en el año 2013, luego se sumaron Perú y Ecuador con decretos de ley sobre migración en el año 2017. Estos son esfuerzos conjuntos muestran el deseo por generar políticas públicas migratorias acordes a la realidad regional (Cepeda 2019).

\section{Políticas públicas migratorias en el Ecuador}

El Ecuador ostenta la calidad de ser un país emisor y receptor de migrantes, sumado a esto se ha intensificado la acogida a los desplazados de otras naciones, estos elementos lo han convertido en el primer país de refugio de América Latina y en los últimos años en un país de tránsito. En este aspecto, el Ecuador con la expedición del Constitución del 2008, plantea la búsqueda consensuada de soluciones al hecho migratorio, garantizando el derecho a migrar y la no discriminación por condiciones migratorias (Quiloango, 2011).

El tema migratorio puesto en este contexto, es decir, como uno de los retos más significativos del Ecuador y su gobierno, requiere respuestas, donde se integren políticas públicas internas y externas con la participación activa de la sociedad civil, las universidades, organismos internacionales, los gobiernos autónomos y por supuesto los migrantes.

Es en sentido, se han establecido políticas que refuerzan las acciones del gobierno en favor de la protección de los derechos de los migrantes, las mismas se desarrollan en los Gobiernos Autónomos Descentralizados Municipales los cuales buscan de acuerdo a la normativa Municipal que se recoge en la Ley Orgánica de Movilidad Humana que en el artículo 165, (Asamblea Nacional , 2017) "formular y planificar el accionar 
conjunto de políticas públicas migratorias que integren a estas personas en espacios de convivencia y desarrollo integral" (p. 23).

La consigna que se debe manejar como elemento integrador es conformar un análisis sincrónico, analítico y con viabilidad jurídica sobre las realidades que se dan en el país en materia migratoria. Existen dicotomías en los procesos, en los cuales se deben enfrentar realidades adversas en cuanto a la formulación de conceptos, que de alguna forma permitan regularizar el estatus migratorio de estas personas. Hoy en día al existir este éxodo masivo de venezolanos a países como Ecuador, Perú, Chile, la fundamentación jurídica y doctrinal para el análisis de la migración no basta, más bien, se requiere generar proyectos regionales, en los cuales se fundamente el verdadero carácter y los alcances que tiene la formulación de este tipo de proyectos.

En los años de historia del Ecuador no se han formulado políticas acordes con los parámetros y normas jurídicas del país en torno a la formulación de una regulación en materia migratoria. En la Constitución del 2008 se buscan consensuar soluciones a los problemas migratorios que tiene el país, es así que se da una nueva reflexión en cuanto a los derechos migratorios a través de un marco jurídico que contempla el reconocimiento de derechos de los migrantes.

Esto se ve plasmado en el artículo 392 de la sección décima población y movilidad humana, que manifiesta: el Estado velara por los derechos de las personas en movilidad humana, y en coordinación con los diferentes niveles de gobierno definirán una política migratoria, en la cual se establecerán planes, programas y proyectos que se sistematizarán con otros Estados y organizaciones de la sociedad civil que trabajen en movilidad humana a nivel nacional e internacional (Asamblea Nacional Constituyente, 2008).

A raiz de la expedicion de la Constitución del 2008, se establece la Ley Orgánica de Movilidad Humana, para la cual se formula un reglamento en el año 2017 y entre sus artículos instituye: normar el ingreso, transito, permanencia, salida y retorno de personas en movilidad humana; establecer requisitos y procedimientos para la 
obtención de una condición migratoria temporal o permanente; y, formular mecanismos para solicitar y obtener protección internacional del Estado (Asamblea Nacional, 2017). En el afán de seguir analizando el marco normativo migratorio en el Ecuador se examina un acápite del Capítulo III Sección 1 art 42-53 de la ley Orgánica de Movilidad Humana (Asamblea Nacional , 2017), el mismo que se fundamenta en una serie de parámetros que regirán para una persona extranjera que se encuentre en el país.

En el art 42 de la norma ibidem se establece lo siguiente: "La Persona extranjera en el Ecuador es aquella que no es nacional del Estado ecuatoriano y se encuentra en el territorio en condición migratoria de visitante temporal o residente" (Asamblea Nacional , 2017, p. 10). Esta definición, hace alusión a la persona que se encuentra en condición migratoria, regular o irregular en el país, así mismo, el art 43 de este cuerpo normativo, denota la ratificación de convenios internacionales que garantizan la libre movilidad humana en el Ecuador, con todos los requerimientos que involucra tal acepción o componente.

Además, a través de su artículo 47, esta ley garantiza los derechos de los migrantes, exponiendo que todos los migrantes tendrán acceso a una libre movilidad, proporcionando el Estado las facilidades para llevar a cabo procesos judiciales. Como se evidencia, en el territorio ecuatoriano existe un cumulo de normas tanto constitucionales como infra constitucionales, que permiten el desarrollo del status migratorio de las personas que se encuentran en esta situación, posibilitándoles a ejercer su legítimo derecho a la defensa.

\section{Derecho al trabajo y salud para personas migrantes}

Ecuador tiene dentro de sus objetivos generar varios consensos referentes a salud pública, ingresando a los migrantes dentro de este componente. Sumado a esto, los preceptos establecidos en el artículo 51 de la Ley de Movilidad Humana, donde plasma el derecho a un trabajo y la seguridad social (Asamblea Nacional, 2017), bajo lo 
indicado, se debe considerar un avance en la formulación y conformación del status migratorio.

A fin de sustentar los derechos de los migrantes, este cuerpo normativo en su artículo 30 sostiene que, para mantener la estadía en el país, los migrantes requieren den un seguro de salud público o privado, dicho seguro debe ser presentado ante la autoridad pertinente en un plazo de treinta días posteriores al otorgamiento de la visa, cumplido esto, se puede obtener la orden de cedulación.

Aunado a lo expuesto, el Reglamento a la Ley de Movilidad Humana, implanta una metodología de aplicación, que se vincula con derechos como el de la salud, por lo tanto, los migrantes se encuentran tutelados bajo la misma norma, pese a esto, el desconocimiento de esta ley, ha llevado a estos grupos a no efectivizar sus derechos, afectando su vida digna. Los mencionados derechos, necesitan ser expuestos, evidenciándose por ejemplo en el artículo 32 del reglamento del Código de movilidad Humana el derecho al trabajo, en este sentido, la persona extranjera, podra solicitar la categoria de trabajo en las coordinaciones zonales respectivas o en las oficinas diplomáticas u oficinas consulares, para dar paso a este pedido, el empleador debe consignar los siguientes requisitos:

a) Acción de personal o contrato de trabajo emitidos por la entidad pública correspondiente o privada.

b) Certificado de registro de contrato, expedido por el Ministerio rector del trabajo.

c) Certificado de no mantener obligaciones pendientes con el servicio de rentas internas, e) Instituto Ecuatoraino de Seguridad Social y la Superintendencia de Compañias, expedido por la autoridad competente en cada caso (Decreto Ejecutivo 111, 2018).

El artículo 52 de la Ley de Movilidad Humana amplía la conformación de derechos supeditados a la salud de las personas, por lo tanto, la finalidad es generar una política integral, que basa su ejecución en la seguridad jurídica, derecho al trabajo y el derecho 
a la salud (Ibídem), complementos que forman parte de la transversalidad de toda política pública en el país.

Del mismo modo, el Gobierno Metropolitano de Quito, también participa en campañas que involucran a los migrantes, ha creado un plan de acción que permite regularizar la permanencia de ciudadanos venezolanos en el Ecuador (Consejo del Distrito Metropolitano de Quito, 2008). Este accionar toma en consideración la Constitución de la República, a traves de la cual se busca implementar un plan de desarrollo integral, donde se exponga las necesidades de los migrantes. Bajo este contexto, la política 9.6 emitida por el Consejo Nacional de Planificación (2017) tiene por finalidad "proteger y promover los derechos de las personas en situación de movilidad humana en el territorio nacional y en el exterior (ver figura 1). En la cual se establece la meta de incrementar la atención a las personas en movilidad humana para la protección de sus derechos, de 699.631 a 750.000 en el año 2021" (pp.106-107).

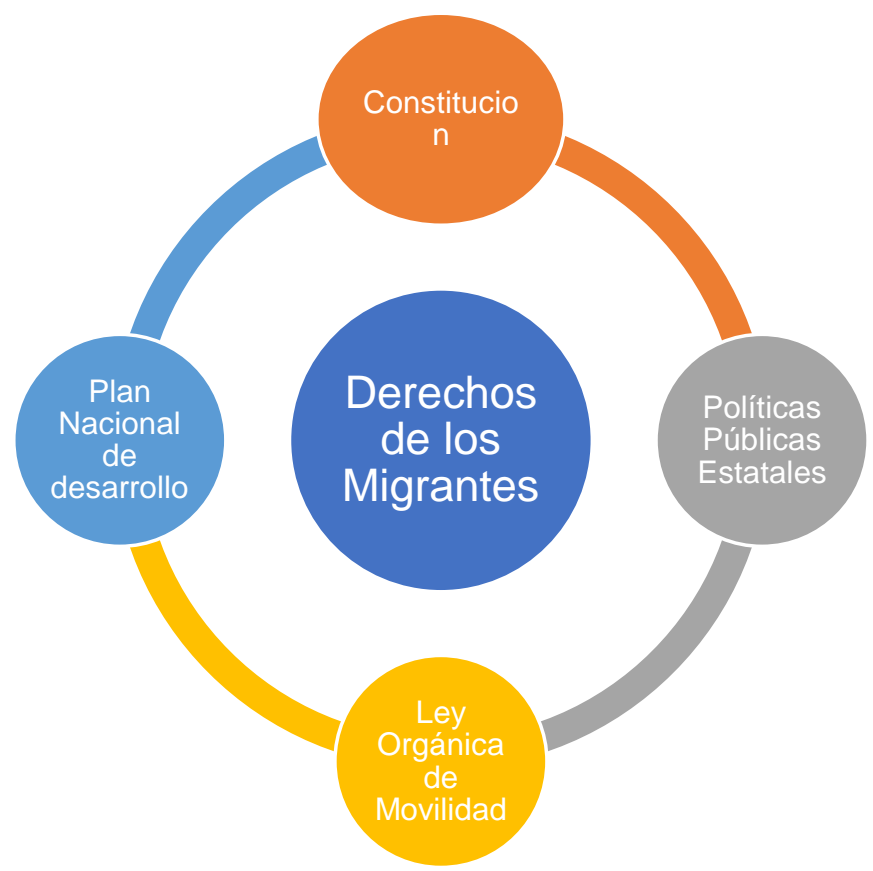

Figura1. Elementos de una política pública. Fuente: ACNUR (2016) 
Según Bustamante (2019) se requiere implementar medidas que garanticen la condición de refugiado para quienes lo necesiten en el estado de acogida, además señala que, se deben articular procesos y planes conjuntos con países vecinos, que permitan concatenar acciones conjuntas que beneficien a los migrantes. El Ecuador, basado en las decisiones de la comunidad internacional ha establecido políticas dirigidas a proteger, regularizar y asistir a la población en situación de movilidad humana, desde las perspectivas de la responsabilidad compartida y la solidaridad internacional (Pérez y Valle, 2010). La comunidad internacional debe seguir fundando la implementación de políticas públicas, que saquen a relucir los cambios de paradigmas, en los cuales se implementen y analicen las necesidades de los migrantes.

\section{METODOLOGÍA}

La investigación se desarrolló mediante la recolección de información de fuentes documentales tales como la Constitución de la República del Ecuador, Ley Orgánica de Movilidad Humana, decretos presidenciales, libros y otros documentos de orden jurídico, por consiguiente, el paradigma cuantitativo aplicado, facilitó el análisis en conjunto de las variables de estudio. Los métodos empleados fueron inductivodeductivo, los mismos que permitieron analizar el alcance de la Constitución de la República del Ecuador, como el compendio de derechos fundamentales indispensables para las personas que se encuentran en condición de movilidad humana; el método de derecho comparado permitió realizar comparaciones de la normativa migratoria de Colombia, Perú y Ecuador; finalmente, el método histórico lógico posibilitó el estudio de la trayectoria de la legislación migratoria en el Ecuador (Pesantez, Erazo, Pozo y Narváez, 2020). 


\section{APORTES GENERADOS}

Ecuador se ha caracterizado por ser un país receptor de migrantes, a consecuencia de los conflictos políticos, sociales, económicos y culturales, de países como Colombia, Cuba y Venezuela, ante esta realidad es necesario formular políticas públicas acorde a la necesidad de estos grupos en condición de movilidad humana, a la vez se debe establecer parámetros en los cuales se ejecuten planes, programas y proyectos en beneficio de los mismos.

Además de la adaptación de políticas públicas viables se debe aplicar los valores fundamentales del ser humano, como es la solidaridad, para así conseguir el objetivo principal que se encuentra consagrado en la Constitución de la República del Ecuador que es el Buen Vivir. En este sentido, se debe recalcar que es el Estado el llamado a formular políticas públicas integrales sustentadas en los derechos humanos, para de esta manera promover el desarrollo de estas personas que requiere atención prioritaria. Es indispensable que los principales actores de la sociedad se involucren y empoderen del tema de la migración y de los derechos que le amparen al trabajador migrante, para que en conjunto y de manera democrática se busquen soluciones a esta problemática. Por consiguiente, es necesario que los mandantes evalúen las tendencias de migración laboral y los problemas de gobernanza conexos a fin de establecer una línea de acción favorable en la labor futura del Ministerio de Relaciones Exteriores.

Se debe señalar que entorno a la defensa de los derechos de los trabajadores migrantes en el Ecuador, aún no se han establecido lineamientos que garanticen su acceso a la seguridad social y a las compensaciones que recibe todo ciudadano ecuatoriano, esto debido a que la Ley de Movilidad Humana, y en el reglamento expedido mediante el decreto 111 de la presidencia de la República, establecen requisitos que obligan a los migrantes a regularizar su estatus en el país, lo que constituye una barrera para el empleo de la población migrante.

La presente investigación pone de manifiesto las distintas esferas que deben ser analizadas por el gobierno para garantizar una gobernanza equitativa y eficiente en el 
marco de la migración laboral, específicamente en lo que respecta a los acuerdos regionales para la contratación de trabajadores migrantes y a la correcta aplicación de las normas vigentes en materia migratoria.

\section{REFERENCIAS CONSULTADAS}

1. Abrahamson, P., \& Ardití , B. (2011). Sentido de pertenencia en sociedades fragmentadas. América latina desde una perspectiva global. Buenos Aires: Grafinor.

2. ACNUR. (2008). Política en Ecuador en materia de Refugiados. Quito: Ministerio de Relaciones exteriores, Comercio e integración.

3. ACNUR. (6 de 03 de 2016). La Agencia de la ONU para los refugiados. Obtenido de https://www.acnur.org/noticias/noticia/2016/3/5b9007344/preguntasfrecuentes-sobre-los-terminos-refugiados-y-migrantes.html

4. Aldana Zavala, J., \& Isea, J. (2019). Migración. Un fenómeno del siglo XXI. IUSTITIA SOCIALIS, 4(6), 52-70. doi:http://dx.doi.org/10.35381/racji.v4i6.288

5. Ansolabehere, K., \& Vásquez, L. (2017). De la injusticia a los derechos: momentos de la construcción de identidad de defensores de derechos humanos. El caso de México. Estudios sociológicos, 517-545.

6. Asamblea Nacional . (2017). Ley Orgánica de movilidad humana. Quito: Registro Oficial.

7. Asamblea Nacional. (2017). Ley Orgánica de movilidad humana. Quito: Registro Oficial No 55.

8. Asamblea Nacional Constituyente. (2008). Constitución del Ecuador. Quito: Asamblea Nacional.

9. Bermudez, Y., Mazuera, R., Albornoz , N., \& Morfle, M. (2018). Informe sobre la movilidad humana venezolana. Caracas: Servicio jesuita a refugiados.

10.BIMID. (2016). Ley de extranjeria en el Perú: Antes y Después. Lima: Universidad Antonio Ruiz de Montoya.

11.Bonilla, A. (2011). Estado del Pais. Informe cero 1950-2010. Quito: Flacso Ecuador. 
12. Bustamente, V. (2019). PLan Especifico de relaciones exteriores y movilidad humana 2019-2030. Quito: Instituto Geografico Militar.

13. Canales, A. (2019). Desarrollo y migración. Desafios y oportunidades en los paises del norte de Centroamerica. México: Cepal.

14. Consejo del distrito Metropolitano de Quito. (08 de 2008). Ordenanza del Distrito metropolitano de Quito No. 271 sobre Movilidad Humana y el Registro Sustitutivo al Acuerdo Minesterial 455. Quito.

15. Constituyente, A. N. (2008). Constitución del Ecuador. Quito: Registro Oficial No. 495.

16. Decreto 0834 (Minsiteriode Relaciones Exteriores Colombia 24 de 04 de 2013).

17. Decreto Ejecutivo 111. (17 de 04 de 2018). Reglamento a la Ley Orgánica de Movilidad Humana. Quito: Registro Oficial No 55.

18. Ermida , O. (2009). Derecho a migrar y derechoa al trabajo. Las migraciones humanas en el Mercosur. Una mirada desde los derechos humanos, 27-34.

19. Gómez , M. (2009). La Política Internacional Migratoria colombiana a principios del siglo XX. Memoria Social, 7-17.

20. Grijalva, A. (2011). Constitucionalismo en Ecuador. Quito: Corte Constitucional para el periodo de transición.

21. Hernández, R., Fernández , C., \& Baptista, M. (2014). Metodología de la Investigación. México: MC Graw Hill.

22. Iranzo, A. (2016). Presentación: Crisis migratorias y concepciones políticas del movimiento humano. Colomb. int, 15-24.

23. Moreno, L. (25 de 07 de 2018). Decreto Presidencial 826. Quito, Ecuador.

24. Perez, N., \& Valle, A. (2010). Los Derechos en la movilidad humana: del control a la protecciòn. Quito: Ministerio de Justicia y derechos Humanos.

25. Pesantez Cárdenas, M. B., Erazo Álvarez, J. C., Pozo Cabrera, E. E., \& Narváez Zurita, C. I. (2020). Análisis del régimen especial de trabajo doméstico desde el principio de igualdad y la prohibición de discriminación. Iustitia Socialis, 266.

26. Quiloango, S. (2011). Políticas públicas migratorias en el Ecuador. Quito: Friedrich Ebert. 
27. Ramirez, F., \& Ramirez, J. (2005). La estampida migratoria ecuatoriana. Quito: Clacso.

28. Ramírez, J. (2014). La Política migratoria en Ecuador. Rupturas, tensiones, continuidades y desafíos. Quito: Instituto de Altos Estudios Nacionales .

29. Van Dijk, T., \& Alsina , R. (2008). Medios de comunicación e inmigración. Murcia: Gallegraf.

30. Velasco , J. (2005). A modo de presentación políticas migratorias una cuestión de justicia. Arbor ciencia pensamiento y cultura, 9-14.

31.Zambrano, H. (2019). El derecho humano a la movilidad humana; su desarrollo en la jurisprudencia de la Corte Constitucional ecuatoriana. Quito: Flacso.

(C2020 por los autores. Este artículo es de acceso abierto y distribuido según los términos y condiciones de la licencia Creative Commons Atribución-NoComercial-Compartirlgual 4.0 Internacional (CC BY-NC-SA 4.0)

(https://creativecommons.org/licenses/by-nc-sa/4.0/). 